\title{
The effect of instructor career motivation on student learning strategies and performance
}

\author{
Paula A. Cruise ${ }^{1, ~ *, ~ C a m i l l e ~ G r a h a m ~}{ }^{2}$ \\ ${ }^{1}$ Faculty of Education, University of Cambridge, Cambridgeshire, UK \\ ${ }^{2}$ Department of Career and Employment Studies, Northern Caribbean University (NCU), Manchester, Jamaica
}

\section{Email address:}

pc378@cam.ac.uk (P. A. Cruise), camille.graham@ncu.edu.jm (C. Graham)

\section{To cite this article:}

Paula A. Cruise, Camille Graham. The Effect of Instructor Career Motivation on Student Learning Strategies and Performance. Education Journal. Vol. 3, No. 6, 2014, pp. 345-354. doi: 10.11648/j.edu.20140306.14

\begin{abstract}
This study investigated and compared instructors' and students' characteristics that determine student learning strategies. Specifically, the study filled a key gap in the literature by examining the relationship between teacher career motivation and student learning effectiveness. Students and instructors from a public school in England completed the Motivated Strategies for Learning Questionnaire (MSLQ) and the Orientations for Teaching Survey (OTS), respectively, as well as demographic questions on age, gender, subject specialism and years of service. Findings revealed a significant effect of instructor career motivation on students' use of resource management strategies $\left(\mathrm{F}_{(4,22)}=5.02 ; \mathrm{p}=.005\right.$; Wilks $\left.\lambda=0.52\right)$, but no effect on students' use of motivation $\left(\mathrm{F}_{(6,20)}=1.23 ; \mathrm{p}=.333\right.$; Wilks $\left.\lambda=0.73\right)$ or cognitive and metacognitive strategies $\left(\mathrm{F}_{(5,21)}=1.10 ; \mathrm{p}=.389 ; \mathrm{Wilks} \lambda=0.79\right)$. Regression analyses found self-efficacy for learning had a mediating effect $\left(\mathrm{R}^{2}=.09 ; \beta=1.96 ; \mathrm{p}=.050\right)$ on the relationship between student gender and academic performance. Findings have implications for class goal-orientation and learning style assessment.
\end{abstract}

Keywords: Teacher Career Motivation, Student Performance, Learning Strategies, Orientations for Teaching Survey, Motivation Strategies to Learn Questionnaire

\section{Introduction}

Instructors motivated to teach have a significant impact on student learning. According to interactionist theorists, learning is a continuous exchange between learner and environment, whereby teachers are masters of the learning environment and are highly influential to both student and context [1] [2] [3]. Affective theorists state that teacher career motivation can impact not only student attitude toward a subject, but also the extent to which students are motivated to engage in subject-relevant learning strategies [4]. Finally, motivation theorists argue that teachers motivated to teach will expend the effort needed to meet the emotional, cognitive and personal needs of the student, thereby igniting motivation in students - a key to ongoing learning. However, beyond the varied theoretical orientations on the importance of teacher motivation to student success, there is limited evidence demonstrating the influence of teacher career motivation on students' use of strategies that lead to learning success.

The current research examined the effect of instructor career motivation on student use of specific learning strategies and subsequent academic performance. We further investigated the effect of student characteristics on students' use of learning strategies and academic performance in order to shed light on differences between the effects of teacher versus student characteristics in facilitating successful learning outcomes. Research on the relationship between student learning strategies and teacher motivation is warranted for three reasons. Firstly, there is an increase in the number of aides being developed to facilitate student learning across various subject curricula [5] [6]. This suggests that understanding factors that drive student success and instructors' ability to identify them remain pertinent issues in educational discourse. Secondly, strategies that facilitate instructor effectiveness across subjects, school ages and countries are key to the development of effective learning interventions [7] [8] [9] [10]. Finally, although there has been extensive research on students' knowledge or awareness of learning strategies, there has been little attention to how the context of learning affects students' use of these strategies [11] [12].

For the past thirty years, motivation has been emphasized as a significant enabler of academic success. Teacher-centric research for example, has examined motivations to teach and the impact (direct and indirect) on student learning [3] [13] [14]. Here, the concept of learning is posited as not purely a 
cognitive activity, but also an affective enterprise - one which requires the motivational drive to achieve the desired result on the part of both teacher and student. Specifically, studies have examined the instructor's role in stimulating student motivation through both instructor influence on the learning context and situation, and the subsequent effect on academic performance [2] [3]. However, the effect of the teacher on students' motivation to employ specific learning strategies remains underexplored.

Researchers argue that intrinsically motivated teachers (possessing personal belief in the social significance of their subject area) will feel obligated to teach their subject effectively, thereby incorporating the most effective teaching strategies which must include student motivation in some form [14]. Indeed research with pre-service elementary science teachers found not only was there an increase in teachers' initial low self-efficacy belief but also an increase in their motivation to learn the subject when motivation-driven teaching strategies were employed. Similarly, an experimental study found that for undergraduate students receiving a piano lesson, there was greater engagement and interest in the learning process among those who were led to believe the instructor was intrinsically motivated (volunteer instructor condition) than among those who were led to believe the instructor was extrinsically motivated (paid instructor condition) [4]. Furthermore, students of the volunteer condition were more likely to engage in self-directed exploration after the piano lesson had ended - an outcome which lends itself to inferences regarding subject-related performance. Despite results demonstrating interaction effects of teacher motivation on both teaching strategies used and student learning, research has not directly investigated the relationship between teacher career motivation and specific learning strategies that students adopt to facilitate learning outcomes.

Socio-cognitive theorists propose that motivation is a dynamic and multi-faceted phenomenon and may vary depending on situation or context in the classroom or school. Students may therefore be motivated in multiple ways. The question is therefore how and why are students motivated not whether motivation exists. In [3]'s overview of the literature on motivation and academic success, four main groupings of motivational constructs were identified - self-efficacy, attribution theory, intrinsic motivation, and goal orientation. Self-efficacy refers to an individual's belief about his/her capabilities in a particular context or task. Self-efficacy is assumed to be situated and contextualized therefore a student may have high self-efficacy for mathematics but low self-efficacy for science. Attribution theory is used to explain when failure or success occurs. Individuals will therefore analyze the situation to determine perceived causes for the failure or success. Intrinsic motivation refers to motivation to engage in an activity for its own sake unlike extrinsic motivation which refers to motivation to engage in an activity as a means to an end. Finally, goal orientation refers to the focus of individuals when engaged in a task. Individuals may either be achievement oriented or mastery oriented. Mastery goals orient learners to develop new skills, improve levels of competence or achieve a sense of mastery based on desired standards. In contrast, task or achievement goals orient learners to determine their ability by outperforming others, surpassing others in achievement or grades and receiving public recognition for superior performance. While each motivational construct was examined in relation to performance from the student perspective, there was clear evidence to support the notion of instructor influence on motivation, whether through influence on environment or utilization of specific teaching strategies.

Preliminary findings on the link between teacher career motivation and student success can be drawn from an investigation into the effect of individual teacher incentives on student performance across more than four thousand schools in the United States [15]. Results revealed that test scores were higher in schools that offered teachers financial incentives for good performance. Although a definitive conclusion that teachers motivated by incentives expend more effort could not be made, results beg the questions: How does teacher career motivation influence learning strategies that students use? What effect does teacher career motivation have on student academic performance? Do teacher career motivation and characteristics have a bigger effect on the strategies that students use to learn than student characteristics themselves?

\subsection{Student Motivation in Student Goal Achievement and Learning Outcomes}

Research emphasizing the student perspective of learning has focused on different types of goal orientations among students, the motivational processes that are associated with these different goals and the conditions that elicit them. This has led to considerable evidence that demonstrates situational demands can affect the salience of specific goals, resulting in differential patterns of cognition, affect and performance [16] [17] [18] [19]. For example, [16] examined the effect of specific motivation patterns on student mastery of tasks and performance goals in classroom settings. Students' perceptions of mastery and achievement goals showed: a) different patterns of relation with learning strategies; b) preference for challenging tasks; c) attitude towards the class; and d) beliefs about success and failure. Findings suggest that a mastery goal orientation may foster a way of thinking that is necessary to sustain student involvement in learning as well as increase the likelihood that students will pursue tasks that foster increments of learning.

Later, [20] examined the effect of classroom situational factors on student achievement motivation and found different goals elicit qualitatively different motivational patterns that are reflected in the broader context of the classroom learning environment. Findings therefore established linkages between environment, goals and student motivation outcomes. However, there remains a lack of evidence identifying the relationship between teacher characteristics, student motivation and strategies that help students to master specific goals. As agents of the goal emphasis of the class, we argue that an instructor's career motivation directly and indirectly affects both the learning strategies adopted by students as well as students' mastery of specific goals.

Linkages between teacher individual characteristics (gender, experience and age) and student goal achievement and 
performance are not definitive. Recent research has found instructor experience and gender play significant roles in facilitating student learning and motivation [21]. Similarly, studies across several cultures (Europe, Africa, India and North America) and subject areas found a direct relationship between teaching experience and student performance, where greater benefits are derived with experience in excess of four years [22] [23] [24] [25]. Without such application, experience was found to have no effect [26]. Furthermore, recent discussion on the effect of gender on learning has resulted in even more debate with results varying according to teaching style, subject area and perceived leadership style, [27] [28] [29].

Given that student learning is the result of an interaction between the learner and his/her environment or learning context [30] [31], and the significance of the teacher's role relative to the success of the student, it stands to reason that this interactive process may extend to teacher-student motivations, where teacher motivations impact approaches students use to facilitate learning and performance irrespective of student individual characteristics.

\subsection{Student Learning Strategies, Goal Achievement and Academic Performance}

The way students organize and coordinate goals and strategies is significantly related to their academic performance [32] [33]. In order to learn effectively, students require a well-developed set of learning strategies, the ability to accurately assess learning tasks, the ability to evaluate and adapt strategies used to accomplish a range of tasks, as well as the ability to plan and monitor the effectiveness of these strategies to determine when and how they learn best [34] [35]. Strategies that students use are linked to the learning approach adopted, quality of learning outcomes and provide useful insights into students' perceptions of learning and learning effectiveness. Furthermore, both students and teachers can benefit from increased understanding of the different learning strategies that students use to learn and how these may change over a course of study [10].

'Learning strategy' refers to any sequence of activities that the student engages in in order to achieve a learning goal. Reference [36] categorized learning strategies in terms of motivational, cognitive and metacognitive and resource management and argued that the kinds of learning strategies that students use are linked to the quality of their learning outcomes. Research has found learning strategies to be particularly helpful to students when learning a new subject [35], as well as the approach of learning students adopt when they study [37]. Studies have also revealed that students' use of different general cognitive strategies such as rehearsal, elaboration, and organization fosters their cognitive engagement in learning and results in higher levels of academic performance [36][38][39][40]. Similarly, metacognitive training has been found to increase students' self-confidence and sense of personal responsibility for their own development [41]. Moreover, students with good metacognitive skills are better critical thinkers, problem solvers and decision-makers than students who are not [42] [43].

In contrast, the relationship between individual variables and use of specific learning strategies is not as clear cut. Scholars do not agree on the effect of student gender on use of learning strategies and its subsequent effect on performance [33]. Studies have examined relationships between students' gender and their goal orientations [44] [45] as well as gender differences in patterns of student learning and achievement and their relationship between motivational and strategies orientations [46] [47] with effects varying across age groups and study design. Furthermore, it has been suggested that, although students may be expected to be more knowledgeable and aware of effective learning strategies, their reported use of strategies was strongly influenced by the perceived goal emphasis of the class [20]. Therefore, the current paper fills this gap by investigating the role of both student and teacher individual characteristics on the learning strategies that students use to succeed in a learning development course.

\section{The Present Study}

The present study aimed to: a) investigate the effect of teacher career motivation on students' use of motivational, cognitive, metacognitive and resource management learning strategies; b) determine the role of teacher characteristics on students' use of specific learning strategies and compare this effect to that of the effect of student characteristics on student use of learning strategies; c) examine the mediating effect of learning strategies used on the relationship between student gender and student academic performance. To this end, a quantitative approach was used to establish the significance of statistical relationships between variables under investigation.

\section{Method}

\subsection{Participants}

Sixty-six students from a learning development course and their 27 instructors participated in the study. The learning and development course was a syllabus elective and aimed to improve students' critical thinking, problem-solving and decision-making skills. Participants were from a public school located in Essex, England. Students were predominantly male $(62.12 \%)$ and ranged in age from $14-17$ years $(\mathrm{M}=15.05 ; \mathrm{SD}$ $=0.98)$. Thirteen male and 14 female instructors participated. Instructors were educated to undergraduate degree level (44.44\%) with $40.74 \%$ indicating post-graduate training. They specialized in a range of subjects including the sciences (22.22\%); arts and humanities (62.96\%); mathematics (18.52\%) and other subjects (18.52\%). Instructors contributed to different modules on the course based on their area of specialism. Teachers ranged in age from $22-63$ years $(\mathrm{M}=40.62$; $\mathrm{SD}=$ $10.29)$ and had an average of 15.83 years' $(S D=11.73)$ service in the profession. The ratio of instructors to students on the course was significantly higher than the UK secondary school class average of $1: 20.51$

\footnotetext{
${ }^{1}$ Education and Skills in Your Area (2012). Department for Education UK. www.eductaion.gov.uk/inyourarea/summary.shtml
} 


\subsection{Measures}

Student Motivation to Learn was measured using the 81-item Motivation Strategies for Learning Questionnaire MSLQ [36]. The MSLQ was designed to assess college students' motivational orientations and their use of different learning strategies. Based on a cognitive view of motivation and learning, items include motivational/affective orientation components (intrinsic goal orientation, extrinsic goal orientation, task value, control of learning beliefs, self-efficacy for learning and performance, and task anxiety), cognitive and metacognitive learning strategy components (rehearsal, elaboration, organization, critical thinking and metacognitive self-regulation), and resource management strategies (time and study environment, effort regulation, peer learning and help seeking). Statements are written in the first person whereby students indicate on a seven-point Likert scale $(1=$ not at all true of me to $7=$ very true of $m e)$ the extent to which each statement reflects them. The MSLQ has been applied to the assessment of learning and motivation for both college [48] [49] [50] and high school students [51] [52] [53] in several countries. Psychometric properties indicate good construct validity $\left(\mathrm{X}^{2} / \mathrm{df}=3.49\right.$; $\left.\mathrm{GFI}=.77, \mathrm{AGFI}=.73\right)$ for all scales with scale alpha reliabilities ranging from .52 to .93 .

Instructor Career Motivation was assessed with the Orientation to Teaching Survey (OTS) by [54]. Consisting of 58 items, the OTS was developed to identify motivations of teachers choosing their career. The scale targets 10 underlying perceptions that teaching: a) is a worthwhile profession; b) is an occupation that provides intellectual stimulation; c) provides an alternative to previously dissatisfying employment; d) provides opportunities to help others; e) provides opportunities to work with children; f) is an occupation with good working conditions; g) provides varied opportunities to work autonomously and with others; h) is an easy occupation into which to gain entry; and i) is a good career or may provide options for career change or advancement. Statements are written in the first person whereby teachers indicate on a five-point Likert scale (1 = Strongly Disagree to $5=$ Strongly Agree) the extent to which each statement reflects them. Psychometric properties indicate good construct validity (mean GFI $=.98$, AGFI $=.92$. RMSR $=.06$ ) with scale alpha reliabilities of original items ranging from .54 to .75 [55]. Table 1 outlines the means, standard deviations, reliability alphas and inter-correlations of all subscales on the OTS administered to the 27 teachers.

\subsection{Procedure and Analytical Strategy}

Questionnaires were distributed to all instructors who contributed to the learning course and all students in attendance on the day of data collection. A letter explaining study objectives was sent to the Deputy Head Teacher who then distributed questionnaires to teachers and students. Teachers were asked to read and explain the instructions to students and provide further clarifications if needed. Data were collected at the end of the 2011 Spring term. Overall academic performance data (across all subjects) data were obtained from the school archives upon receipt of the questionnaires. To ensure anonymity and data protection, ethics forms drafted by the school were signed by the researchers.

Table 1. Means, standard deviations, scale alphas and inter-correlations of dimensions of teacher career motivations (OTS)

\begin{tabular}{|c|c|c|c|c|c|c|c|c|c|c|c|c|c|c|c|}
\hline & Variables & Mean & SD & Scale Alpha & 1 & 2 & 3 & 4 & 5 & 6 & 7 & 8 & 9 & 10 & 11 \\
\hline 1. & Orientations to Teaching Survey (OTS) & 2.55 & .48 & .92 & - & & & & & & & & & & \\
\hline 2. & Working with children & 2.83 & .79 & .74 & $.61^{* *}$ & - & & & & & & & & & \\
\hline 3. & Worth of teaching & 2.75 & .69 & .75 & $.87^{* *}$ & $.47^{*}$ & - & & & & & & & & \\
\hline 4. & Intellectual stimulation & 3.57 & .85 & .82 & $.66^{* *}$ & $.40^{*}$ & $.69^{* *}$ & - & & & & & & & \\
\hline 5. & Ease of entry/work & 1.88 & .62 & .55 & .34 & -.06 & .11 & .05 & - & & & & & & \\
\hline 6. & Patterns of interaction & 2.15 & .59 & .52 & $.69^{* *}$ & .17 & $.64^{* *}$ & .32 & .30 & - & & & & & \\
\hline 7. & Dissatisfaction with other occupation & 1.38 & .52 & .61 & $.39^{*}$ & .11 & .25 & -.10 & $.54^{* *}$ & $.48^{*}$ & - & & & & \\
\hline 8. & Conditions of work & 2.97 & .79 & .73 & $.56^{* *}$ & .16 & .35 & .31 & .25 & .18 & .18 & - & & & \\
\hline 9. & Helping others & 3.07 & .73 & .80 & $.83^{* *}$ & $.71^{* *}$ & $.77^{* *}$ & $.57^{* *}$ & .01 & $.54^{* *}$ & .06 & .24 & - & & \\
\hline 10. & Career considerations & 2.42 & .69 & .61 & $.77^{* *}$ & .15 & $.74^{* *}$ & $.52^{* *}$ & $.39^{*}$ & $.70^{* *}$ & .34 & $.43^{*}$ & $.48^{*}$ & - & \\
\hline 11. & Influence of others & 1.90 & .72 & .74 & $.77^{* *}$ & $.46^{*}$ & $.53^{* *}$ & .24 & .23 & $.51^{* *}$ & .38 & $.50^{* *}$ & $.67^{* *}$ & $.42^{*}$ & - \\
\hline
\end{tabular}

ANOVAs, MANOVAs and Ordinary Least Square (OLS) Regressions were used to analyze the data. Reference [57] simple mediation analysis was used to determine the mediating effect of learning strategies on the relationship between student gender and academic performance. Non-parametric bootstrap coefficient estimates were used to generate bias-corrected confidence intervals to determine the reliability of the data and the practical effect of significant findings [56]. Prior to analysis, all variables were mean-centered. Data were analyzed using STATA version 12.

\section{Results}

\subsection{Instructor Career Motivation and Student Learning Strategies}

Twenty-seven students were randomly selected to match the teacher sample. To identify the effect of teacher career motivation on student learning strategies, a series of one-way 
factorial multivariate analysis of variance (MANOVA) were conducted using teacher career motivation dimensions as the independent variables, and student learning dimensions as the dependent variables.

We further examined the relationship between instructor characteristics (age, gender and years of service) and student use of learning strategies. OLS regressions revealed that instructor gender was a significant predictor of student help-seeking $\left(\mathrm{R}^{2}=0.23 ; \beta=0.92 ; \mathrm{p}=.019,95 \%\right.$ confidence interval $(\mathrm{CI})=0.17-1.67)$; whilst instructor age $\left(\mathrm{R}^{2}=0.23 ; \beta\right.$ $=0.04 ; \mathrm{p}=.045,(\mathrm{CI})=0.00-0.9)$ and years of service $\left(\mathrm{R}^{2}=\right.$ $0.23 ; \beta=-0.05 ; \mathrm{p}=.050,(\mathrm{CI})=-0.10-0.00)$ were significant predictors of student use of peer learning as a strategy. Instructor characteristics did not significantly predict student use of any motivation or cognitive and metacognitive learning strategies.

Table 2. Between subject effects of teachers motivated by influence of others on student learning strategies

\begin{tabular}{|c|c|c|c|c|c|c|}
\hline & Learning Strategies & df & Mean Square & $\mathbf{F}$ & Sig. & Partial Eta Squared \\
\hline \multirow{5}{*}{ Motivation } & Intrinsic goal orientation & 3 & 1.38 & 1.55 & .228 & .17 \\
\hline & Extrinsic goal orientation & 3 & 3.07 & 3.66 & .027 & .32 \\
\hline & Task value & 3 & 0.68 & 0.86 & .478 & .10 \\
\hline & Self-efficacy for learning & 3 & 0.98 & 1.06 & .383 & .12 \\
\hline & Test anxiety & 3 & 0.67 & 0.57 & .634 & .07 \\
\hline \multirow{4}{*}{ Cognitive and Metacognitive } & Rehearsal & 3 & 2.41 & 4.65 & .011 & .38 \\
\hline & Organisation & 3 & 0.16 & 0.15 & .926 & .02 \\
\hline & Critical thinking & 3 & 0.89 & 1.33 & .290 & .15 \\
\hline & Metacognitive self-regulation & 3 & 0.57 & 1.44 & .257 & .16 \\
\hline \multirow{4}{*}{ Resource Management } & Time and study environment & 1 & 2.99 & 6.96 & .014 & .22 \\
\hline & Effort regulation & 1 & 7.67 & 14.74 & .001 & .37 \\
\hline & Peer learning & 1 & 1.57 & 2.25 & .146 & .08 \\
\hline & Help seeking & 1 & 0.95 & 1.19 & .285 & .05 \\
\hline
\end{tabular}

Table 3. Differences between male and female students across motivation to learn strategies

\begin{tabular}{|c|c|c|c|c|c|}
\hline & \multirow{2}{*}{$\mathbf{t}$} & \multirow{2}{*}{ df } & \multirow{2}{*}{ Sig } & \multicolumn{2}{|c|}{ 95\% Confidence Interval } \\
\hline & & & & Lower & Upper \\
\hline Intrinsic goal orientation & -0.52 & 64 & .602 & -0.54 & 0.31 \\
\hline Extrinsic goal orientation & -0.66 & 64 & .514 & -0.69 & 0.35 \\
\hline Task value & -1.19 & 64 & .239 & -0.66 & 0.17 \\
\hline Control of learning beliefs & -0.51 & 64 & .613 & -0.56 & 0.33 \\
\hline Self-efficacy for learning & 2.01 & 64 & .049 & .0 .00 & 0.88 \\
\hline Rehearsal & 0.09 & 64 & .927 & -0.38 & 0.42 \\
\hline Elaboration & -0.28 & 64 & .778 & -0.50 & 0.38 \\
\hline Organisation & -0.50 & 64 & .621 & -0.56 & 0.34 \\
\hline Critical thinking & 1.52 & 64 & .134 & -0.09 & 0.69 \\
\hline Metacognitive self-regulation & 0.01 & 64 & .994 & -0.32 & 0.32 \\
\hline Time and study environment & -0.28 & 64 & .782 & -0.40 & 0.30 \\
\hline Effort regulation & 0.76 & 64 & .447 & -0.28 & 0.62 \\
\hline Help seeking & -2.16 & 64 & .034 & -0.89 & -0.04 \\
\hline
\end{tabular}

\subsection{Instructor Career Motivation, Student Learning Strategies and Academic Performance}

OLS regression analyses were conducted to identify the relationship between instructor career motivation, instructor characteristics, student learning strategies and student academic performance. Results revealed a good model that predicted student use of resource management strategies $\left(\mathrm{F}_{(8}\right.$, $\left.{ }_{18)}=2.23 ; \mathrm{p}=.074 ; \mathrm{R}^{2}=0.50\right)$. Instructors who were motivated by the influence of others $(\beta=21.68 ; \mathrm{p}=.030,95 \%$ confidence interval $(\mathrm{CI})=2.37-40.99)$, years of service $(\beta=$ $0.96 ; p=.022,95 \%(\mathrm{CI})=0.16-1.77)$, instructor age $(\beta=$ $-1.00 ; \mathrm{p}=.007,(\mathrm{CI})=-1.70--0.31)$, and students using peer-learning strategies $(\beta=11.67 ; p=.006,95 \%(C I)=3.77$
- 19.57) were the best predictors of higher levels of student academic performance. Findings indicate that younger and earlier career instructors significantly predicted student academic performance. Given the moderate sample size, we then used non-parametric bootstrapping methodology to test the validity of significant predictors based on 20,000 bootstrap samples - ten percent of the approximately 200,000 secondary school teachers in the $\mathrm{UK}^{2}$ [56]. Bootstrap confirmed the model was good $\left(\mathrm{R}^{2}=0.51\right.$; Root $\left.\mathrm{MSE}=11.25\right)$. Peer-learning strategy $(\mathrm{p}=.015 ;$ Bias $=-.099 ; 95 \%$ Bias-Corrected Confidence Interval $(\mathrm{BC})=3.13-20.91)$, instructor gender $(\mathrm{p}$ $=.020 ;$ Bias $=-.252 ; 95 \%(\mathrm{BC})=0.49-23.39)$, instructor age

\footnotetext{
${ }^{2}$ Department of Education UK
} 
$(\mathrm{p}=.009 ;$ Bias $=-.001 ; 95 \%(\mathrm{BC})=-1.61--0.22)$, and instructor years of service $(\mathrm{p}=.021$; Bias $=-.012 ; 95 \%(\mathrm{BC})=$ $0.24-1.96)$ were significant predictors of student academic performance.

\subsection{Student Characteristics, Learning Strategies and Academic Performance}

Using all 66 student cases, we first examined the relationship between student gender, age, learning strategies and academic performance. OLS regressions revealed gender as a significant predictor of academic performance when motivation $\left(\mathrm{R}^{2}=.21 ; \beta=2.42 ; \mathrm{p}=.019,95 \% \mathrm{CI}=-1.87-\right.$ 19.58), cognitive and metacognitive $\left(\mathrm{R}^{2}=.19 ; \beta=2.06 ; \mathrm{p}\right.$ $=.044,95 \% \mathrm{CI}=0.24-16.18)$ and resource management learning strategies $\left(\mathrm{R}^{2}=.18 ; \beta=2.22 ; \mathrm{p}=.030,95 \% \mathrm{CI}=0.85\right.$ - 16.66) were included in the model. Further inspection revealed significant differences between girls' and boys' self-efficacy for learning and performance $\left(\mathrm{t}_{(64)}=2.12\right.$, $\mathrm{p}$ $=.038)$, test anxiety $\left(\mathrm{t}_{(64)}=-3.24, \mathrm{p}=.002\right)$, and help-seeking $\left(\mathrm{t}_{(65)}=-1.99, \mathrm{p}=.034\right)$. Boys in general were more confident in their ability to master a task whilst girls were on average, more anxious about test performance and used help-seeking as a resource management strategy. There were no significant gender differences in use of cognitive and metacognitive learning strategies.

We then examined the mediating effect of learning strategies (self-efficacy for learning and performance, test anxiety and help-seeking) on the relationship between gender and academic performance. OLS regression analysis revealed a significant mediating effect of self-efficacy for learning $\left(\mathrm{R}^{2}\right.$ $=.09 ; \beta=1.96 ; \mathrm{p}=.050,95 \% \mathrm{CI}=-0.34-7.67)$ on the relationship between gender and academic performance. Given the moderate sample size, we then used non-parametric bootstrapping methodology [56] to test the validity of indirect effects in simple mediation based on 30,000 bootstrap samples - approximately $30 \%$ of the 89,683 secondary school student population in Essex. Analysis revealed the indirect effect of gender on academic performance through self-efficacy for learning and performance (mediator) was significant $(\beta=1.94$; $\mathrm{p}=0.052$ ) with a point estimate of -.004 and a $95 \%$ bias-corrected bootstrap confidence interval of $2.40-17.75$. There was no significant mediating effect of either test anxiety $\left(\mathrm{R}^{2}=.09 ; \beta=-.17 ; \mathrm{p}=.188,95 \%(\mathrm{CI})=-6.83-1.37\right)$ or help-seeking $\left(\mathrm{R}^{2}=.08 ; \beta=.09 ; \mathrm{p}=.467,95 \%(\mathrm{CI})=-0.34-\right.$ 7.67) on the relationship between student gender and academic performance.

A MANOVA revealed there was a significant effect of student age group on learning strategies adopted $\left(\mathrm{F}_{(2,63)}=1.79\right.$, $\mathrm{p}=.017$; Wilks' $\lambda=0.42$; partial $\eta 2=0.35)$. There was a significant effect of age on time and study environment $\left(\mathrm{F}_{(2)}=\right.$ $3.96, p=.024$; partial $\eta 2=0.11)$ and student effort regulation $\left(F_{(2)}=10.32, p \leq .000 ;\right.$ partial $\left.\eta 2=0.25\right)$. Bonferroni post hoc tests revealed that for time and study environment, there were significant differences between $\leq 14$ yrs. and 15-16 yrs. age groups $(\mathrm{T}=.47 ; \mathrm{p}=.024)$ and the $\leq 14 \mathrm{yrs}$. and $\geq 17 \mathrm{yrs}$. age group $(T=.87 ; p=.026)$. Similarly, for effort regulation, there were significant differences between $\leq 14 \mathrm{yrs}$. and 15-16 yrs. age groups $(T=.83 ; p \leq .000)$ and the $\leq 14 \mathrm{yrs}$. and $\geq 17 \mathrm{yrs}$. age group $(\mathrm{T}=1.53 ; \mathrm{p} \leq .000)$.

\section{Discussion}

\subsection{Discussion of Findings}

The role of instructor career motivation in students' use of learning strategies is underexplored. Furthermore, previous research documenting the effect of teacher and student characteristics on student performance remains inconclusive. In this article we report the findings of a small scale exploratory study that: a) investigated the effect of instructor career motivation on students' use of motivational, cognitive and metacognitive, and resource management learning strategies; b) compared the effect of teacher and student characteristics on student learning strategies; and c) examined the mediating effect of learning strategies on the relationship between student gender and academic performance.

Findings showed that instructors who were motivated to pursue their careers by the influence of others (an extrinsic motivator) had a significant effect on students' use of resource management strategies, specifically students' use of effective time and study management and effort regulation. This supports earlier conceptual arguments that learning strategies play a key role in not only helping students assess learning tasks but help students to monitor their own learning success and adapt accordingly [34]. Effort regulation refers to the ability to control and maintain one's effort to learn in the face of distractions and uninteresting tasks. Findings suggest that students' resource management strategies may be influenced by teachers who also benefited from these through the influence of others.

Reference [4] found that instructor motivation to teach can impact both student attitudes toward a subject as well as students' motivation to engage in subject-relevant learning activities. Findings here support their arguments and further highlight that not only is effective educational instruction achieved when there is a match between instructor teaching style and student learning style [58], but that learning strategies adopted by students appear to actively mirror teacher career motivators. Future research is needed to further explore this mirror by investigating the class performance and learning strategies of students with similar learning styles to those of their teachers compared to that of students and teachers with discordant learning styles.

According to previous research, intrinsically motivated teachers will encourage student motivation through the incorporation of more effective teaching strategies [14]. In contrast, findings here emphasize the importance of extrinsic motivators in helping students identify and use learning strategies effectively. With previous research also identifying incentives as a predictor of student performance [15] there is a need to further investigate independent and combined effects of other teacher intrinsic and extrinsic motivators on other measures of student academic success. Indeed instructor career motivation may further shed light on the strategies 
students adopt to deal with negative school experiences that may also affect student academic performance. We therefore encourage future researchers to examine the effect of teacher career motivation on additional desirable student outcomes.

Interestingly, the present research generated no significant effect of teacher career motivation on student use of cognitive and metacognitive learning strategies. This may be partly due to the students' ability as well as the objective of the learning development course. It is unclear to what extent student cognitive ability may have impacted findings given previous assertions that higher-achieving students may be more knowledgeable of effective learning strategies [20]. However, with the objective of the learning development course being to master critical thinking, problem solving and decision-making skills, it is feasible to expect that resource management strategies may play a more significant role [59]. With a master goal orientation, teachers appear to be encouraging strategies that sustain student involvement in learning and foster increments of learning through effort regulation and study time management [16].

We further investigated the effect of teacher individual characteristics (age, gender, and years of service) on students' use of learning strategies. Male instructors were more likely to influence students' help-seeking whilst younger and early career teachers significantly predicted students' peer learning. Whilst results from the current study are in line with previous research findings that teacher individual variables play significant roles in facilitating student learning [21] [28], they do not support research findings that individual teacher characteristics influence student motivation [27]. We found no significant effect on students' intrinsic goal orientation, extrinsic goal orientation, task value, control beliefs about learning or self-efficacy for learning and performance. Similarly, teacher individual characteristics played no role in students' use of cognitive and metacognitive learning strategies. This may be because the goal emphasis of the class was mastery-based. Since our findings showed a learning goal orientation and a relative ability goal orientation were more related to positive motivational beliefs and higher cognitive strategy use [60], resource-management strategies may be a more complementary fit to courses with a mastery emphasis.

In fact the best predictors of students' performance on the learning development course were instructors motivated by the influence of others, students using peer-learning strategies, instructor age and years of service respectively. This finding demonstrates the interaction between teacher career motivation and characteristics, and student learning strategies in producing desired academic outcomes. Furthermore, with teacher career motivation having the largest beta weight, results emphasize the need for further research to establish the influence of teacher career motivation in student performance whilst raising the question: To what extent did teacher career motivation influence student academic performance in previous studies?

To compare the effect of the teacher relative to that of the student, we examined the relationship between student characteristics, learning strategies and academic performance and found student gender to be a significant predictor of academic performance when motivation, cognitive and metacognitive and resource management strategies were used. Whereas teacher career motivation and individual characteristics influenced students' use of resource management strategies, student gender predicted students' use of motivation (self-efficacy for learning and performance; test anxiety), and resource management strategies (help-seeking). Similarly student age significantly influenced students' time and study environment and study effort regulation. Students in the $14-15$ year age group were significantly more effective at managing their time and study environment as well as controlling their effort and attention in the face of distractions and uninteresting tasks compared to students two grades above them. Findings lead us to conclude that teacher career motivation has a similar effect of student age on students' use of resource management strategies, as both play a significant role in determining task mastery.

Finally, we found girls were significantly more anxious about test performance and used help-seeking as a resource management strategy whilst boys were significantly more confident in their ability to master a task. If task achievement rather than task mastery is the emphasis of the class, then this potentially explains inconsistencies in findings of gender differences in academic performance [32] [33] as variability in results may be due to the goal orientation of the class rather than age-group and study design discrepancies[46]. A further test of mediation found self-efficacy for learning and performance (a self-appraisal of one's ability to master a task and one's confidence in one's ability to perform a task), significantly mediated the effect of gender on academic performance - thereby confirming that student motivation influences gender differences in student success.

\subsection{Limitations}

Although the present study is the first to systematically examine the effect of teacher career motivation on students' use of learning strategies, one could argue that the size of the teacher sample is relatively small. However, the sample was sufficient to help detect statistically significant effects. In addition, with the student sample size being moderate, we believe that application of the bootstrapping technique validates significant findings of the role learning strategies play in the relationship between gender and academic performance. Furthermore, as previously found by [15], in light of the research being conducted in a public school in the UK, we are unable to definitively state the extent to which findings can be generalized to state school settings or other cultures.

\subsection{Implications}

At a theoretical level, results provide evidence that learning strategies adopted by students reflect both the interactionist [1] [2] [3] and affective perspectives [4] of learning whereby teacher career motivations and characteristics influence student approaches to learning as well as student success in learning. However, more research is needed to explore other 
individual teacher characteristics and traits that determine students' use of specific learning strategies in a range of contexts. There is ongoing demand for psychometrically robust assessments that determine teacher and student complementary styles [33] [58]. Based on findings here, we too encourage researchers to develop learning style inventories that help both students and teachers gain awareness and knowledge of their respective approaches to learning. Research of this nature will not only generate valid assessments but contribute to the development of tailored interventions and aides that facilitate learning across subject curricula [5] [6]. A psychometrically robust measure will also enable the development of models that demonstrate the combined interaction effect of teacher and student characteristics, teacher and student learning orientations, teacher and student motivation in determining student learning outcomes. Furthermore, with teacher individual variables playing a significant role in student learning strategies and academic performance, future work in this field should also explore the extent to which these effects are maintained over time.

Finally, findings have implications for the importance of class goal orientation in the identification and use of effective learning strategies. Given that resource management strategies appear to be connected to the mastery orientation of the class, it is recommended that future research investigate the degree to which goal orientation moderates the effects of both teacher and student traits in determining use of specific learning strategies and student performance.

\subsection{Conclusion}

There is no evidence of the effect of teacher career motivation on student learning strategies and academic success despite the extant literature on the importance of teacher motivation in learning. Similarly, there is no definitive evidence on teacher and student characteristics that determine students' use of specific learning strategies despite the widely accepted view that learning strategies help students to learn effectively. We found that teachers motivated to pursue their careers by the influence of others significantly affected students' use of resource management strategies on a learning development course but played no role in students' use of motivation or cognitive and metacognitive learning strategies. For students, gender and age were determinants of learning strategies used but motivation strategy (self-efficacy for learning and performance) mediated the effect of student gender on performance. Findings have significant implications for the goal emphasis of classes and teacher effectiveness and as such reiterate the need to develop learning style assessments that aim to match the teachers' style to that of students'.

\section{References}

[1] Alexander, P.A. \& Murphy, P.K. (1998). The research base for APA's learner-centered psychological principles. In N.L. Lambert \& B.L. McCombs (Eds.), Issues in school reform: A sampler of psychological perspectives on learner-centered schools.

[2] Christophel, D.M. (1990). The relationships among teacher immediacy behaviors, student motivation, and learning. Communication Education, 39(4), 323-343. DOI: 10.1080/03634529009378813.

[3] Linnenbrink, E.A. \& Pintrich, P.R. (2002). Motivation as an enabler for academic success. School Psychology Review, 31(3), 313-327.

[4] Wild, T.C., Enzle, M.E. \& Hawkings, W.L. (1992). Effects of perceived extrinsic versus intrinsic teacher motivation on student reactions to skill acquisition. Personality and Social Psychology Bulletin, 18(2), 245-251. DOI: 10.1177/0146167292182017.

[5] Harden, R.M. (2002). Learning outcomes and instructional objectives: is there a difference? Medical Teacher, 24 (2), 151-155. DOI: 10.1080/0142159022020687.

[6] Shaughnessy, A.F. \& Slawson, D.C. (1999). Are we providing doctors with the training and tools for lifelong learning? British Medical Journal, $319: 1280 . \quad$ DOI: http://dx.doi.org/10.1136/bmj.319.7220.1280.

[7] Ballinger, R., \& Ballinger, V. (1982). Steps in managing the diagnostic prescriptive process in the foreign language classroom. In J. W. Keefe (Ed.), Student learning styles and brain behavior: Programs, instrumentation, research (pp. 33-37). Reston, VA: National Association of Secondary School Principals.

[8] Dunn, R. (1984). Learning style: State of the science. Theory into Practice, Matching Theory and Learning Styles 23, 10-19.

[9] Elliot, A.J., McGregor, H.A. \& Gable, S. (1999). Achievement goals, study strategies, and exam performance: A mediational analysis. Journal of Educational Psychology, 91(3), 549-563. DOI: $10.1037 / 0022-0663.91 .3 .549$

[10] de la Harpe, B. \& Radloff, A. (2001). The value of assessing learning strategies for effective learning and teaching: strengthening the partnership between learners and teachers. Retrieved on 13.03.2013 from https://www.herdsa.org.au/wp-content/uploads/conference/2001/Paper s/Delaharpe_Radloff.pdf.

[11] McKeachie, W.J., Pintrich, P.R. \& Lin, Y.G. (1985). Teaching learning strategies. Educational Psychologist 20, 153-160. DOI: $10.1207 / \mathrm{s} 15326985 \mathrm{ep} 2003$ _5

[12] Thomas, J.W. \& Rohwer, W.D. (1986). Academic studying: The role of learning strategies. Educational Psychologist, 21(1/2), 19-41. DOI: 10.1207/s15326985ep2101\&2_2

[13] Subasi, G. (2009). I want to become an English Teacher in Turkey because.... International Journal of Arts and Sciences, 3(5), 137-175. Retrieved from http://openaccesslibrary.org/images/Gonca_Subasi.pdf.

[14] Watters, J.J. \& Ginns, I.A. (2000). Developing motivation to teach elementary science: Effect of collaborative and authentic learning practices in preservice education. Journal of Science Teacher Education, 11(4), 301-321. DOI: 10.1023/A: 1009429131064

[15] Figlio, D.N., \& Kenny, L.W. (2007). Individual teacher incentives and student performance. Journal of Public Economics 91, 901-914. 
[16] Ames, C. (1984). Achievement attributions and self-instructions under competitive and individualistic goal structures. Journal of Educational Psychology, 76(3), 478-487.

[17] Ames, C., Ames, R., \& Felker, D. W. (1977). Effects of competitive reward structure and valence of outcome on children's achievement attributions. Journal of Educational Psychology, 69, 1-8.

[18] Covington, M. V. (1984). The self-worth theory of achievement motivation: Findings and implications. Elementary School Journal, 85, 5-20

[19] Covington, M.V. \& Omelich, C.L. (1984). Task-oriented versus competitive learning structures: Motivational and performance consequences. Journal of Educational Psychology, 76(6), 1038-1050. DOI: 10.1037/0022-0663.76.6.1038

[20] Ames, C. (1992). Classrooms: Goals, structures, and student motivation. Journal of Educational Psychology, 84(3), 261-271. DOI: $10.1037 / 0022-0663.76 .3 .478$

[21] Chudgar, A. \& Sankar, V. (2008). The relationship between teacher gender and student achievement: evidence from five Indian states. Compare: A Journal of Comparative Education, 38(5), 627-642. DOI: 10.1080/03057920802351465

[22] Chargois, T.B., Irons, E.J. \& Carslon, N.L. (2011). Class size, school size, teacher experience and successful classroom strategies: Implications for fifth-grade African American students' Math achievement. National Social Science Journal, 36(1), 22-30.

[23] O'Connor, E.A. \& Fish, M.C. (1998). Differences in the classroom systems of expert and novice teachers. Paper presented at the Annual Meeting of the American Educational Research Association, San Diego, C.A.

[24] Winans, D. (2005). It's hard to stick around. NEA Today, 23(8), 41.

[25] Yara, P.O. \& Wanjohi, W.C. (2011). Performance determinants of Kenya Certificate of Secondary Education (KCSE) in Mathematics of secondary schools in Nyamaiya Division, Kenya. Asian Social Science, 7(2), 107-112.

[26] Dahar, M.A., Dahar, R.A., Dahar, R.T. \& Faize, F.A. (2011). Impact of teacher quality on the academic achievement of students at secondary stage in Punjab (Pakistan). European Journal of Social Sciences, 19(1), 97-105.

[27] Howsen, R.M. \& Trawick, M.W. (2007). Teachers, race and student achievement revisited. Applied Economics Letters, 14(14), 1023-1027. DOI: 10.1080/13504850600706453

[28] Hoffman, F. \& Oreopoulos, P. (2009). A professor like me. Journal of Human Resources, 44(2), 479-494. DOI:10.3368/jhr.44.2.479

[29] Chudgar, A. \& Sankar, V. (2008). The relationship between teacher gender and student achievement: evidence from five Indian states. Compare: A Journal of Comparative Education, 38(5), 627-642. DOI: 10.1080/03057920802351465

[30] Vermunt, J.D. \& Vermetten, Y.J. (2004). Patterns in student learning: Relationships between learning strategies, conceptions of learning, and learning orientations. Educational Psychology Review, 16(4), 359-384. DOI: 10.1007/s10648-004-0005-y

[31] Vermunt, J.D. (2005). Relations between student learning patterns and personal and contextual factors and academic performance. Higher Education, 49, 205-234. DOI: 10.1007/s10734-004-6664-2.

[32] Dowson, M., \& McInerney, D. M. (2003). What do students say about their motivational goals? Towards a more complex and dynamic perspective on student motivation. Contemporary Educational Psychology, 28, 91-113.

[33] Dowson, M. \& McInerney, D.M. (2004). The development and validation of the Goal Orientation and Learning Strategies Survey (Goals-S). Educational and Psychological Measurement 64(2), 290-310. $10.1177 / 0013164403251335$

[34] Biggs, J.B., \& Moore, P.J. (1993). The Process of Learning (3rd edition). Englewood Cliffs, N.J: Prentice Hall.

[35] Garner, R. (1990). When children and adults do not use learning strategies: Toward a theory of settings. Review of Educational Research, 60, 517-529. DOI: $10.3102 / 00346543060004517$

[36] Pintrich, P. R., Smith, D. A. F., Garcia, T., \& McKeachie, W. J. (1993). Reliability and predictive validity of the Motivated Strategies for Learning Questionnaire (MSLQ). Educational and Psychological Measurement, 53 (3), 801 -813. DOI: $10.1177 / 0013164493053003024$

[37] Biggs, J. (1999). What the student does: Teaching for enhanced learning. Higher Education Research and Development, 18(1), $57-75$.

[38] Dickinson, D.J., \& O'Connell, D.Q. (1990). Effect of quality and quantity of study on student grades. Journal of Educational Research, 83, 227-231.

[39] Weinstein, C.E., \& Mayer, R.E. (1986). The teaching of learning strategies. In M. Wittrock (Ed.), Handbook of Research on Teaching (pp. 3 15-327). New York, NY: Macmillan

[40] Zimmerman, B. J., Greenberg, D., \& Weinstein, C. E. (1994). Self-regulating academic study time: A strategic approach. In D H. Schunk \& B. J. Zimmerman (Eds.), Selfregulation of Learning and Performance. Issues and educational applications (pp. 181- 199). Hillsdale, New Jersey: Lawrence Erlbaum Associates.

[41] McCombs, B.L. \& Marzano, R.J. (1990). Putting the self into self-regulating learning: The self as agent in integrating will and skill. Educational Psychologist, 25, 51-69. DOI: 10.1207/s15326985ep2501_5.

[42] Ewell-Kumar, A. (1999). The influence of metacognition on managerial hiring decision making: Implications for management development. Dissertation Abstracts International Section A: Humanities and Social Sciences, 59 (10-A).

[43] Heath, S.B. (1983). Ways with words: Language, life, and work in communities and classrooms. Cambridge, MA: Cambridge University Press.

[44] Kaplan, A. \& Maehr, M.L. (1999). Achievement goals and student well-being. Journal of Contemporary Educational Psychology 24 (4), 330-358.

[45] Midgley, C., Arunkumar, R. \& Urdan, T.C. (1996). "If I don't do well tomorrow, there's a reason": Predictors of adolescents' use of academic self-handicapping strategies. Journal of Educational Psychology, 88(3),423-434. DOI: 10.1037/0022-0663.88.3.423. 
[46] Bouffard, T., Boisvert, J., Vezeau, C. \& Larouche, C. (1995). The impact of goal orientation on self-regulation and performance among college students. British Journal of Educational Psychology 65, 317-329. DOI: 10.1111/j.2044-8279.1995.tb01152.x

[47] Wentzel, K. R. (1991b). Social competence at school: Relations between social responsibility and academic achievement. Review of Educational Research, 61, 1-24.

[48] Karabenick, S.A \& Knapp, J.R (1991). Relationship of academic help seeking to the use of learning strategies and other instrumental achievement behavior in college students. Journal of Educational Psychology 83 (2), 221-230.

[49] Magno, C. (2011). Validating the academic self-regulated learning scale with the Motivated Strategies for Learning Questionnaire (MSLQ) and learning and study strategies inventory (LASSI). The International Journal of Educational and Psychological Assessment, 7(2), 56-73.

[50] Pintrich, P.R. (2004). A conceptual framework for assessing motivation and self-regulated learning in college students. Educational Psychology Review, 16(4), 385-407. DOI: 10.1007/s10648-004-0006-x

[51] Karadeniz, S., Buyukozturk, S., Akgun, O. E., Cakmak, E. K., \& Demirel, F. (2008) The Turkish adaptation study of motivated strategies for learning questionnaire (MSLQ) for 12-18 year old children: Results of confirmatory factor analysis. The Turkish Online Journal of Educational Technology, 7(4), 108-117.

[52] Liu, E.Z.F. \& Lin, C.H. (2010). The survey study of Mathematics motivated strategies for learning questionnaire (MMSLQ) for Grade 10-12 Taiwanese students. The Turkish Online Journal of Educational Technology, 9(2), 221-233.

[53] Pintrich, P.R. \& DeGroot, E.V. (1990). Motivational and self-regulated learning components of classroom academic performance. Journal of Educational Psychology, 82(1), 33- 40. DOI: $10.1037 / 0022-0663.82 .1 .33$

[54] Ferrell, C. M., \& Daniel, L. G. (1993). Construct validation of an instrument measuring teacher career motivations (Paper presented at the Annual Meeting of the Mid-South Educational Research Association, New Orleans, LA). East Lansing, MI: National Center for Research on Teacher Learning. (ERIC Document Reproduction Service No. ED365719)

[55] Sinclair,C.; Dowson, M. \& McInerney, D.M, (2006). Motivations to teach: Psychometric perspectives across the first semester of teacher education. Teacher College Record 108 (6), $1132-1154$.

[56] Preacher, K.J. \& Hayes, A.F. (2008). Asymptotic and resampling strategies for assessing and comparing indirect effects in multiple mediator models. Behavior Research Methods 40 (3), 879-891. DOI: 10.3758/BRM.40.3.879

[57] Baron, R. M., \& Kenny, D. A. (1986). The moderator-mediator variable distinction in social psychological research: Conceptual, strategic, and statistical considerations. Journal of Personality and Social Psychology, 51(6), 1173.

[58] Wang, K.H., Wang, T.H., Wang, W.L. \& Huang, S.C. (2006). Learning styles and formative assessment strategy: Enhancing student achievement in web-based learning. Journal of Computer Assisted Learning, 22(3), 207-217. DOI: 10.1111/j.1365-2729.2006.00166.x

[59] Wolters, C. A. (1999). The relation between high school students' motivational regulation and their use of learning strategies, effort, and classroom performance. Learning and Individual Differences, 11(3), 281-299.

[60] Wolters, C. A., Yu, S. L., \& Pintrich, P. R. (1996). The relation between goal orientation and students' motivational beliefs and self-regulated learning. Learning and individual differences, 8(3), 211-238. 